\title{
Scar endometriosis following caesarean section: a rare case report
}

\author{
Manisha Sharma $^{1}$, Ruchira Nautiyal ${ }^{1}$, Jaya Chaturvedi ${ }^{2}$, Surbhi Bhargava $^{1}$
}

${ }^{1}$ Department of Obstetrics \& Gynaecology, SRHU, Doiwala, Dehradun, Uttarakhand, India
${ }^{2}$ Department of Obstetrics \& Gynaecology, AIIMS, Rishikesh, Dehradun, Uttarakhand, India

Received: 25 March 2015

Revised: 08 April 2015

Accepted: 05 May 2015

\section{*Correspondence:}

Dr. Manisha Sharma,

E-mail: mannisharmambbs@gmail.com

Copyright: (C) the author(s), publisher and licensee Medip Academy. This is an open-access article distributed under the terms of the Creative Commons Attribution Non-Commercial License, which permits unrestricted non-commercial use, distribution, and reproduction in any medium, provided the original work is properly cited.

\begin{abstract}
Endometriosis is presence of functioning endometrial tissue (glands and stroma) outside the uterine cavity. Endometriosis can sometimes occur in previous surgical scar. Scar endometriosis is rare and difficult to diagnose. It mostly follows obstetrical and gynaecological surgeries. We present here a case report of a patient who developed scar endometriosis following a caesarean section which was dealt adequately in the subsequent caesarean section.
\end{abstract}

Keywords: Scar endometriosis, Caesarean section

\section{INTRODUCTION}

Endometriosis is defined as presence or growth of ectopic endometrial tissue. Endometriosis occurs in 5\%-10\% of all women often resulting in debilitating pain and infertility. ${ }^{1}$ The most common sites of involvement in decreasing order of frequency are the ovaries, pelvic peritoneum, deep pelvic sub-peritoneal spaces, intestinal system and urinary system. ${ }^{2}$ Scar endometriosis is a rare entity. Majority of scar endometriosis have been reported after obstetrical or gynaecological procedures such as caesarean delivery, hysterotomy, hysterectomy, episiotomy and tubal ligations. ${ }^{3}$ The reported incidence of scar endometriosis after caesarean section is $0.3-0.4 \%$ and following hysterotomy is $1-2 \% .^{4}$ Although rare, but with increasing number of caesarean section this complication is not infrequent.

\section{CASE REPORT}

A 35 years old, Para 1 Live1 presented with a painful lump on the left lateral aspect of pfannenstiel incision 6 months after a caesarean section. FNAC of the lump was taken which reported scar endometriosis and patient was symptomatically managed. Following a period of secondary infertility for 4 years she conceived. After conception, the symptoms and the lump disappeared. Her antenatal period was uneventful and at 38 weeks period of gestation, elective LSCS was done. Per operatively, pin point greenish black spots were found in subcutaneous tissue suggestive of old haemorrhage (Figure 1, 2).

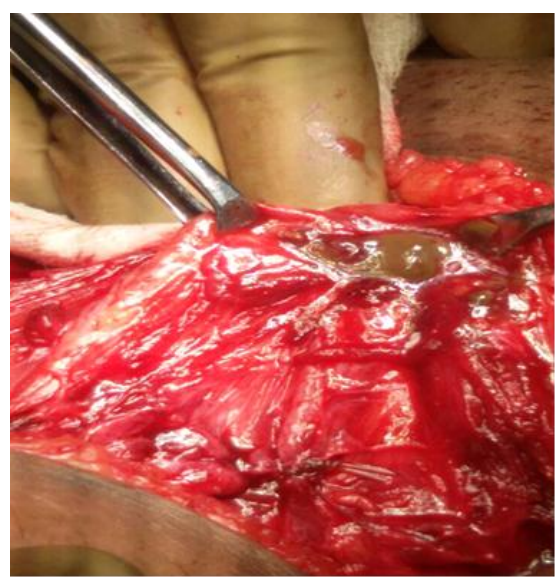

Figure 1: Showing greenish black spots of endometriosis on rectus sheath. 


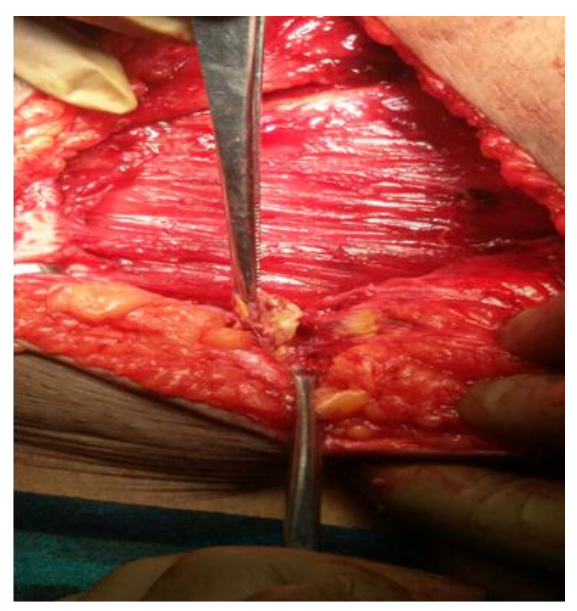

Figure 2: Showing greenish black spots of endometriosis on subcutaneous tissue.

Thorough and wide spread excision of fibrofatty tissue with part of rectus sheath was done and was sent for histopathological examination. Report confirmed scar endometriosis (Figure 3). Post-operative period was uneventful. A clinical follow up and USG was done after two months (Figure 4). No abnormalities were detected.

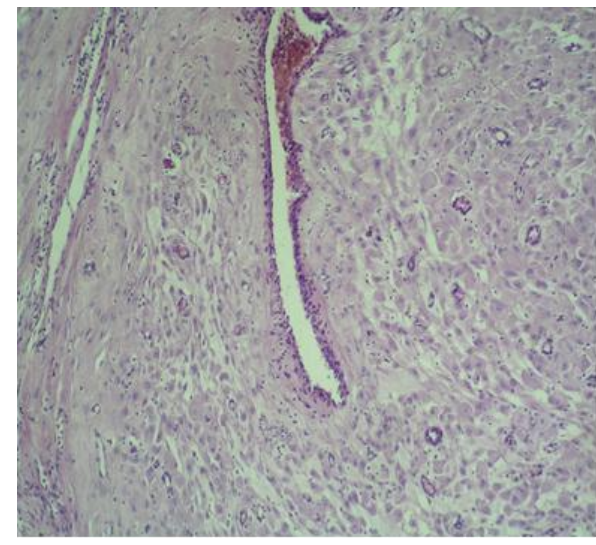

Figure 3: Histopathological report showing endometrial glands, stroma and haemosiderin pigment.

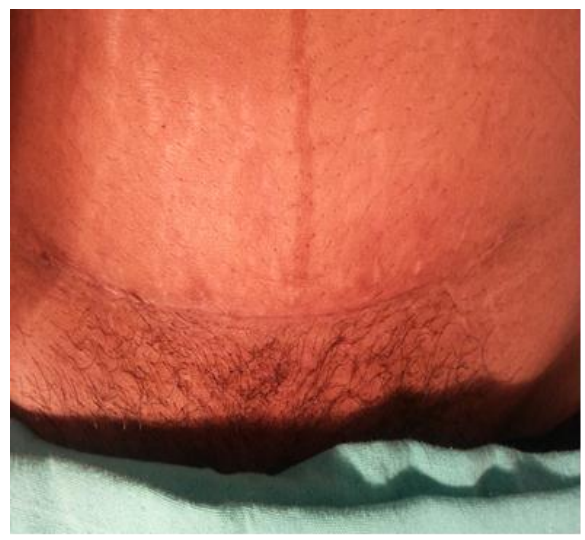

Figure 4: First follow up picture of scar taken after two months.

\section{DISCUSSION}

The most common site for external endometriosis is within the pelvis and has been reported to occur in $44 \%$ of women undergoing laparoscopy. ${ }^{5}$ However, extra pelvic endometriosis is a fairly uncommon disorder and difficult to diagnose. The various sites for extra pelvic endometriosis are bladder, kidney, bowel, omentum, lymph nodes, lungs, pleura, extremities, umbilicus, hernia sacs and abdominal wall. ${ }^{6}$ Scar endometriosis is a rare entity reported in the gynaecological literature and presents in women who have undergone previous abdominal and pelvic operation. ${ }^{1}$ The condition is commonly seen in females of reproductive age. Failure to close the parietal and visceral peritoneum in the caesarean section may be related to greater rates of scar endometrioma. ${ }^{5}$ Time interval between operation and presentation has varied from 3 months to 10 years in different series. ${ }^{7}$ Many theories as to the cause of scar endometriosis has been postulated, however the most generally accepted theory is implantation of decidual cells during various surgical procedures which subsequently proliferate or induce metaplasia in the surrounding cells under the influence of estrogen to cause endometriosis. ${ }^{3}$ Inadequate immunogenic response to retrograde flow is also hypothesised.

The diagnosis of scar endometriosis may be very challenging. Cyclical changes in the intensity of pain and size of endometrial implants during menstruation are usually characteristics of classical endometriosis. However, in the largest reported series to date, only $20 \%$ of patients exhibited these symptoms. Patient usually complains of tenderness to palpation and a raised unsightly hypertrophied scar or lump. ${ }^{1}$ It can mimic surgical lesions like hernia, lipoma, cyst, abscess etc.

The worth of various methods of investigation such as USG, CT, MRI, Doppler sonography in the diagnosis is not clear. Imaging procedures help rather than confirm in obtaining differential diagnosis. Fine needle aspiration cytology was reported in some studies for confirming the diagnosis. Histology is the hallmark of diagnosis. It is satisfied if endometrial glands, stroma and hemosiderin pigments are seen. Local wide excision with atleast $1 \mathrm{~cm}$ margin is accurate treatment of choice in scar endometriosis. Medical treatment with danazol, progesterone and $\mathrm{GnRH}$ produces partial recovery and mostly recurs after cessation of treatment. The incidence of concomitant pelvic endometriosis with scar endometriosis has been reported to be from $14.3 \%$ to $26 \%{ }^{7}$ At this point post-operative follow up with gynaecologist is preferable. Recurrence of the lesion warrants exclusion of malignancy.

\section{CONCLUSION}

Scar endometriosis is rare and often illusive diagnosis, that can lead to both patient and surgeon's frustration. One should maintain a high level of suspicion in any 
women presenting with pain at incisional site, most commonly following pelvic surgery. A thorough history and physical examination should be performed and differential diagnosis should be kept in mind. Proper care and technique during caesarean section is suggested especially for resident doctors.

Funding: No funding sources

Conflict of interest: None declared

Ethical approval: Not required

\section{REFERENCES}

1. Wolf G, Singh K. Cesarean scar endometriosis: a review. Obstet Gynecol Surv. 1989;44:89-95.

2. Bazot M, Darai E, Hourani R, Thomassin I, Cortez A, Uzan S, et al. Deep pelvic endometriosis: MR imaging for diagnosis and prediction of extension of disease. Radiology. 2004;232:379-89.
3. Padmanabhan LD, Mhaskar R, Mhaskar A. Scar endometriosis. J Obstet Gynaecol India. 2003;53:5961.

4. Chatterjee SK. Scar endometriosis: a clinicopathological study of 17 cases. Obstet Gynecol. 1980;56:81-4.

5. Rawson JM. Prevalence of endometriosis in asymptomatic women. J Reprod Med. 1991;36:5135 .

6. Markham SM, Carpenter SE, Rock JA. Extra pelvic endometriosis. Obstet Gynecol Clin North Am. 1989;16:193-219.

7. Chatterjee SK. Scar endometriosis: a clinicopathological study of 17 cases. Obstet Gynecol. 1980;56:81-4.

DOI: $10.18203 / 2320-1770 . i j r \operatorname{cog} 20150119$

Cite this article as: Sharma M, Nautiyal R, Chaturvedi J, Bhargava S. Scar endometriosis following caesarean section: a rare case report. Int J Reprod Contracept Obstet Gynecol 2015;4:884-6. 